\title{
Teaching volunteer educators to tinker
}

\author{
Steven Worker is helping to improve out-of-school-time pedagogy.
}

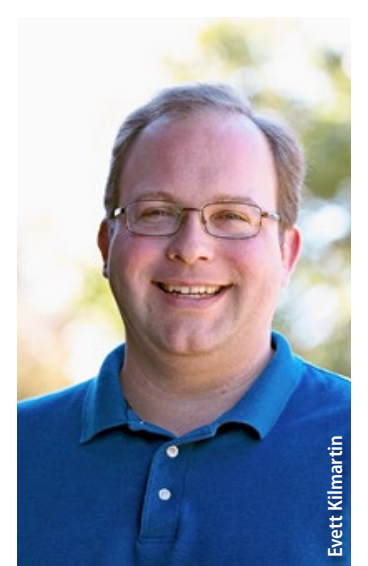

Steven Worker
D

n May 2016, Steven Worker began as a 4-H Youth

Development Advisor for Marin, Sonoma and Napa

counties. His mission is to study pedagogical practices of $4-\mathrm{H}$ volunteer educators and use that to improve future 4-H volunteer development efforts.

Worker holds a Ph.D. in education (emphasis in learning sciences) from UC Davis. As part of his dissertation (Worker 2016), he studied how volunteer educators engage youth in science and engineering education (see page 208 of this issue). He observed $4-\mathrm{H}$ youth and adults engaged in $4-\mathrm{H}$ projects using the $4-\mathrm{H}$ Junk Drawer Robotics curriculum, which emphasizes inquiry-based pedagogy - basically, tinkering. While the volunteer instructors were provided with guidelines that emphasized a hands-on, tinkering-oriented approach, Worker found that they interpreted the directions in a variety of ways, based on their own ideas and values about teaching. Some, for instance, spent some of the class time lecturing.

Volunteer educators for 4-H science and engineering programs may need content expertise, but Worker says that just having that is not enough. They also need to understand how their pedagogical practices help shape learning outcomes. Volunteers bring their own goals, values and assumptions when working with youth. There's value in understanding and engaging these underlying values, otherwise "we won't know the full story of what contributes to 4-H learning experiences," Worker says.

To meet the needs of $4-\mathrm{H}$ youth, UC Cooperative Extension needs to expand what counts as learning, according to Worker et al. (2017). To this end, Worker in his dissertation studied expanded indicators of learning, such as cultivating dispositions (expressed, for instance, as resiliency, connection and creativity), learning to use tools, and improved motivation for learning. Worker has thought extensively about how best to explore out-of-school-time pedagogies to help reach those outcomes.
Worker joined UC Cooperative Extension in December 2001 at the State 4-H Office, where he was responsible for adolescent leadership development, recognition programs, and technology education. He's also a $4-\mathrm{H}$ veteran - as a youth he was a Santa Barbara County All-Star 4-H County Ambassador, and then a 4-H State Ambassador.

Worker participates in Cooperative Extension teams piloting new models of volunteer development that expand on traditional one-time workshops. These new models of volunteer development, including communities of practice and lesson study, involve iterative cycles of 4-H volunteers learning together and improving their pedagogical practices. CA

-Editors

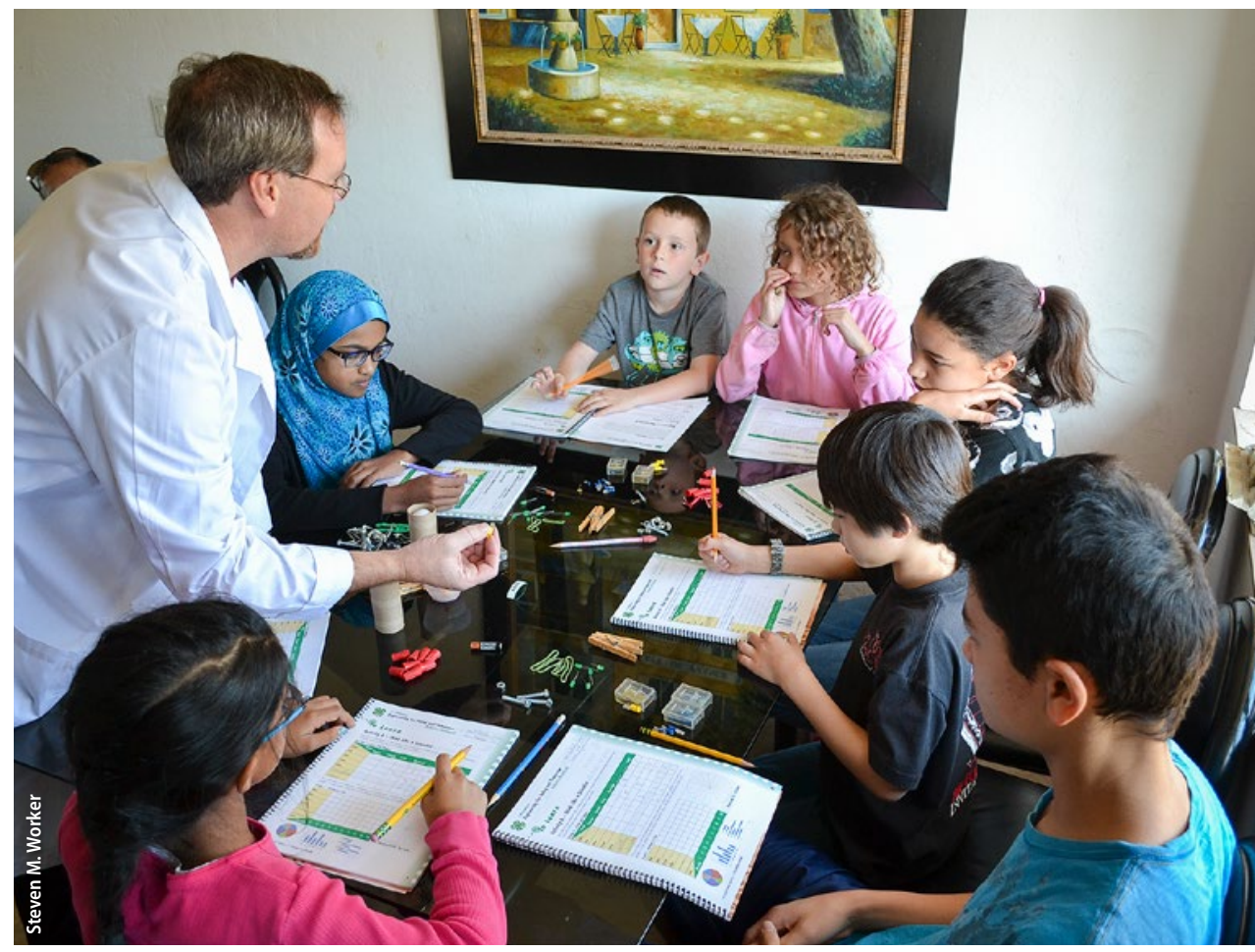

4-H youth engage in a Junk Drawer Robotics activity.

\section{References}

Worker SM. 2016. Volunteer educators' influence on youth participation and learning in 4-H STEM learning by design programs. Doctoral dissertation, Office of Graduate Studies, UC Davis, CA. https://search.proquest.com/openview/4cd4bccb6eb2ac40804 $877 \mathrm{c} 814 \mathrm{bb} 135 \mathrm{c} /$.

Worker SM, Ouellette KL, Maille A. 2017. Redefining the concept of learning in Cooperative Extension. J Extension 55(3). www.joe. org/joe/2017june/a3.php. 